\title{
Can a multidisciplinary approach slow renal progression in CKD patients?
}

\author{
Ampornpan Theeranut ${ }^{1,2}$, Nonglak Methakanjanasak ${ }^{1}$, Pattama Surit ${ }^{1}$, Junto Srina ${ }^{3}$, Dhavee Sirivongs ${ }^{5}$, \\ Doangjai Adisuksodsai ${ }^{3}$, Sunee Lertsinudom ${ }^{4}$, Kittisak Sawanyawisuth ${ }^{5 凶}$ \\ 1. Department of Adult Nursing, Faculty of Nursing, Khon Kaen University, Khon Kaen, 40002 Thailand. \\ 2. Research and Training Center for Enhancing Quality of Life of Working Age People, Khon Kaen University, Khon Kaen, Thailand. \\ 3. Department of Medicine, Chumpae Hospital, Khon Kaen, 40002Thailand. \\ 4. Department of Clinical Pharmacy, Faculty of Pharmaceutical Sciences, Khon Kaen University, Khon Kaen, 40002 Thailand. \\ 5. Department of Medicine, Faculty of Medicine, Khon Kaen University, Khon Kaen, 40002 Thailand. \\ $\triangle$ Corresponding author: Kittisak Sawanyawisuth, MD, PhD, Department of Medicine, Faculty of Medicine, Khon Kaen University, Khon Kaen, 40002, \\ Thailand, Email: kittisak@kku.ac.th, Tel: 66-43-363664, Fax: 66-43-348399 \\ () The author(s). This is an open access article distributed under the terms of the Creative Commons Attribution License (https://creativecommons.org/licenses/by/4.0/). \\ See http://ivyspring.com/terms for full terms and conditions.
}

Received: 2020.09.12; Accepted: 2021.02.15; Published: 2021.03.03

\begin{abstract}
Background: Several randomized controlled trials have examined the benefits of multidisciplinary CKD care on estimated glomerular filtration rate (eGFR). But, the results are inconclusive.

Purpose: This study aimed to evaluate whether or not multidisciplinary CKD care was beneficial in terms of CKD progression.

Methods: This is a randomized controlled trial and conducted at community hospital, Thailand. The inclusion criteria were patients with age of 18 years or older and diagnosed with up to stage 3 b CKD based on the KDIGO guidelines. Eligible patients divided into two groups: intervention and control group. The intervention group received a type of multidisciplinary treatment, while patients in the control group received the standard treatment administered at the outpatient clinic. The primary outcome was eGFR outcomes at three months after enrollment.

Results: During the study period, there were 334 patients who met the study criteria. Eligible patients were divided into two groups: intervention (166 patients; $49.70 \%$ ) and control (168 patients; 50.30\%). There were three outcomes that differed significantly between the two groups at 3 months: mean difference of eGFR from baseline, proportion of patients with eGFR decline greater than $4 \mathrm{~mL} / \mathrm{min} / 1.73$ $\mathrm{m}^{2}$, and difference in CKD stage from baseline. A significantly higher percentage of patients in the intervention group experienced CKD improvement by one stage ( $24.10 \%$ vs $5.95 \%$ ), and a significantly lower percentage experienced decline by one stage (8.43\% vs $35.12 \%)$ than in the control group.

Conclusion: Slower renal progression in patients with up to stage $3 b$ CKD was shown in patients who were treated by a multidisciplinary approach.
\end{abstract}

Key words: CKD, education, glomerular filtration rate.

\section{Introduction}

Chronic kidney disease (CKD) is defined as the presence of albuminuria greater than or equal to 30 $\mathrm{mg} /$ day or an estimated glomerular filtration rate (eGFR) of less than $60 \mathrm{~mL} / \mathrm{min} / 1.73 \mathrm{~m}^{2}$ for more than three months regardless of cause [1]. The condition is a known cardiovascular risk factor. A study found that patients with eGFR below $60 \mathrm{ml} / \mathrm{min} / 1.73 \mathrm{~m}^{2}$ had a $13 \%$ higher risk of cardiovascular death [2]. Additionally, CKD patients require renal replacement therapy at a rate of approximately 1.6 per 100 patient-years [3]. Interventions are required in order to reduce both cardiovascular risk and renal progression.

Reversible causes of renal failure, such as hypovolemia and NSAID use, should generally be avoided. Additionally, ACEI/ARB may slow renal progression in particular situations [1]. Statin therapy has been shown to prevent major cardiovascular 
events by $20 \%$ with $1 \mathrm{mmol} / \mathrm{L}$ of LDL-c reduction [4]. Other possible treatments include protein restriction, smoking cessation, and blood pressure/glucose control. Due to the variety of treatments required for CKD, a multidisciplinary approach may be needed [5]. Additionally, the incidence of CKD is increasing leading to a need to improve primary healthcare system by the multidisciplinary approach [6].

Previous studies have shown that cost at dialysis initiation and risk of death were lower at multidisciplinary CKD clinics than usual care at 942 USD vs 2410 USD and hazard ratio of 2.17, respectively [7, 8]. Dialysis initiation and mortality were significantly lower in multidisciplinary treatment group than the control $(13.9 \%$ vs $43 \%$; $p<$ 0.001 and $1.7 \%$ vs $10.1 \% ; p<0.001)$ as well as medical cost reduction [9, 10]. However, there are still conflicting data on multidisciplinary management on eGFR. Two studies showed improvement of eGFR by multidisciplinary management by $2.74-13.39 \mathrm{ml} / \mathrm{min}$ $[11,12]$, while a systematic review and two randomized controlled trials did not [13-15]. This study aimed at adding a study on evaluating whether or not multidisciplinary CKD care was beneficial in terms of CKD progression.

\section{Methods}

This was an intervention study conducted at Chumpae Hospital in Khon Kaen, Thailand. This hospital is a large community hospital with 150 beds and serves a population of 123,739 people. The inclusion criteria were patients with age of 18 years or older and diagnosed with up to stage $3 \mathrm{~b}$ CKD based on the KDIGO guidelines. The exclusion criteria were those end stage renal disease hospitalized and required dialysis, unable to participate the study toward the end, or had co-morbid diseases that needed further treatment such as cancer, HIV infection, or systemic lupus erythromatosus. The study period was between January 2017 and April 2018. Eligible patients were randomly assigned to either the intervention or control group using a simple random sampling method.

The intervention group received a type of multidisciplinary treatment called the Chumpae model for delaying dialysis in CKD patients. This model is an intervention based on the chronic care model and consists of four principle systems, as follows: delivery, clinical information, decision support, and self-management support. The delivery system is a healthcare system for individual patients in which treatment is administered by internists, registered nurses, and pharmacists. For complicated cases, specialized nurses are assigned to care for individual patients based on social and cultural factors. The clinical information system provides updated, systematic clinical evidence for the patients and care team. The decision support system encourages decision making through the exchange of ideas among patients. Finally, the self-management support system empowers patients by employing the specialized nurses and expert patients to facilitate self-monitoring and self-efficacy.

The procedures were performed in an outpatient setting with six steps: 1) clinical information evaluation and decision support by specialized nurse 2) self-management support by expert patients and pharmacist 3) decision support by internists 4) appointment and follow-up by specialized nurse 5) medications by pharmacist and 6) self-management support by patients and caregivers. The specialized nurse also contacted patients by phone regarding any concerns or issues they had while at home. The media used in the intervention included a log book, a video regarding CKD care, a CKD pamphlet, and advice from the expert patients. Patients in the control group received the standard treatment administered at the outpatient clinic. The CKD treatment plans for patients in both groups were decided on by an attending physician. Baseline characteristics and clinical variables were assessed. The eGFR outcomes of eligible patients were then evaluated at three months.

\section{Sample size calculation}

As previously reported [11], the mean difference of eGFR between the multidisciplinary management and non- multidisciplinary management group was $13.39 \mathrm{ml} / \mathrm{min}$. For a power of $90 \%$ and confidence of $99 \%$, the sample size in each arm was 148 . With a $10 \%$ drop out rate, the required of study population was 163 patients.

\section{Statistical analysis}

Data were reported as mean (SD) for numerical variables and number (percentage) for categorical variables. Comparisons between groups were computed by using descriptive statistics at both baseline and three months. An unpaired t-test was used for a comparison of numerical variables with normal distribution, while Chi- square test or Fisher Exact test was used when appropriate for a comparison of categorical variables. All statistical analysis was conducted using STATA software, version 10.1 (College Station, Texas, USA). The study protocol was approved by the institutional review board, Khon Kaen University, Thailand (HE602078).

\section{Results}

During the study period, there were 334 patients 
who met the study criteria. Eligible patients were divided into two groups: intervention (166 patients; $49.70 \%$ ) and control (168 patients; 50.30\%). Five of the studied variables were non-significant including sex, religion, and proportions of patients with dyslipidemia, gout, and coronary artery disease (Table 1). The control group had significantly higher income than the intervention group (5585 vs 2516 baht/month; $p$ value $<0.001$ ) as well as education levels, co-morbid diseases, and previous experiences on CKD (Table 1). In terms of physical signs, the intervention group had significantly higher waist circumference $(91.12$ vs $76.73 \mathrm{~cm})$ but lower diastolic blood pressure (72.66 vs $74.82 \mathrm{mmHg}$ ) than the control group (Table 2).

Table 1. Baseline characteristics of patients with chronic kidney disease (CKD) who received an intervention for delaying dialysis (intervention group) compared to controls.

\begin{tabular}{|c|c|c|c|}
\hline Factors & $\begin{array}{l}\text { Intervention group } \\
(\mathrm{n}=166)\end{array}$ & $\begin{array}{l}\text { Control group } \\
(\mathrm{n}=168)\end{array}$ & $\mathrm{p}$ value \\
\hline Age, years & $66.06(7.94)$ & $68.66(8.93)$ & 0.005 \\
\hline Male sex & $64(38.55)$ & $64(38.10)$ & 0.999 \\
\hline Marital status & & & 0.033 \\
\hline Single & $4(2.42)$ & $5(3.07)$ & \\
\hline Married & $130(78.79)$ & $143(87.73)$ & \\
\hline Widowed & $30(18.18)$ & $13(7.98)$ & \\
\hline Divorced/separated & $1(0.61)$ & $2(1.23)$ & \\
\hline Religion: Buddhism & $165(99.40)$ & $168(100.0)$ & 0.315 \\
\hline Highest education & & & $<0.001$ \\
\hline No & $8(4.91)$ & $20(12.20)$ & \\
\hline Primary school & $147(90.18)$ & $80(48.78)$ & \\
\hline Secondary school & $6(3.68)$ & $45(27.44)$ & \\
\hline College or higher & $2(1.23)$ & $13(7.93)$ & \\
\hline Occupation & & & $<0.001$ \\
\hline Unemployed & $89(53.61)$ & $51(30.54)$ & \\
\hline Agriculturist & $57(34.34)$ & $34(20.36)$ & \\
\hline Employee & $12(7.23)$ & $61(36.53)$ & \\
\hline Government officer & $2(1.20)$ & $18(10.78)$ & \\
\hline Mean (SD) income, Baht & 2516.77 (4163.34) & $\begin{array}{l}5585.35 \\
(5566.83)\end{array}$ & $<0.001$ \\
\hline Primary caregiver & & & 0.038 \\
\hline Spouse & $71(42.77)$ & $48(32.43)$ & \\
\hline Children & $90(54.22)$ & $89(60.14)$ & \\
\hline Siblings & $2(1.20)$ & $10(6.76)$ & \\
\hline Cousin/relative & $2(1.20)$ & $1(0.68)$ & \\
\hline $\begin{array}{l}\text { Previous experience with } \\
\text { nutrition in CKD }\end{array}$ & $40(24.10)$ & $56(57.73)$ & $<0.001$ \\
\hline $\begin{array}{l}\text { Previous experience with safety } \\
\text { drugs in CKD }\end{array}$ & $27(16.27)$ & $57(58.76)$ & $<0.001$ \\
\hline $\begin{array}{l}\text { Previous experience with } \\
\text { deteriorating renal function }\end{array}$ & $12(7.27)$ & $41(42.27)$ & $<0.001$ \\
\hline \multicolumn{4}{|l|}{ Co-morbid diseases } \\
\hline Hypertension & $152(91.57)$ & 138 (82.63) & 0.021 \\
\hline Diabetes & $120(72.29)$ & $156(93.41)$ & $<0.001$ \\
\hline Dyslipidemia & $76(45.78)$ & $74(44.31)$ & 0.826 \\
\hline Gout & $14(8.43)$ & $9(5.39)$ & 0.289 \\
\hline Coronary artery disease & $6(3.61)$ & $1(0.60)$ & 0.067 \\
\hline
\end{tabular}

At baseline, the intervention group had significantly lower eGFR than the control group but the eGFR was higher at 3 months in the intervention group ( 48.77 vs $47.89 \mathrm{ml} / \mathrm{min} / 1.73 \mathrm{~m}^{2} ; \mathrm{p}$ value $\left.=0.395\right)$. There were three outcomes that differed significantly between the two groups at 3 months: mean difference of eGFR from baseline, proportion of patients with eGFR decline greater than $4 \mathrm{~mL} / \mathrm{min} / 1.73 \mathrm{~m}^{2}$, and difference in CKD stage from baseline (Table 3). A significantly higher percentage of patients in the intervention group experienced CKD improvement by one stage $(24.10 \%$ vs $5.95 \%)$, and a significantly lower percentage experienced decline by one stage $(8.43 \%$ vs $35.12 \%)$ than in the control group.

Table 2. Physical factors and laboratory results of patients with chronic kidney disease (CKD) who received an intervention for delaying dialysis (intervention group) compared to controls.

\begin{tabular}{llll}
\hline Factors & $\begin{array}{l}\text { Intervention group } \\
(\mathrm{n}=166)\end{array}$ & $\begin{array}{l}\text { Control group } \\
(\mathrm{n}=168)\end{array}$ & $\mathrm{p}$ value \\
\hline Body mass index, kg/m2 & $25.33(3.94)$ & $25.06(4.10)$ & 0.564 \\
Waist, cm & $91.12(9.94)$ & $76.73(19.08)$ & $<0.001$ \\
Systolic blood pressure, mmHg & $135.36(15.30)$ & $138.41(17.03)$ & 0.087 \\
Diastolic blood pressure, mmHg & $72.66(8.64)$ & $74.82(9.15)$ & 0.027 \\
HbA1C, \% & $7.82(2.07)$ & $8.02(2.05)$ & 0.419 \\
LDL-c, mg/dL & $103.87(36.18)$ & $97.69(40.33)$ & 0.142 \\
HDL-c, mg/dL & $44.40(13.06)$ & $42.63(13.02)$ & 0.215 \\
\hline Note. Data presented as mean (SD). & &
\end{tabular}

Table 3. Glomerular filtration rate (eGFR) and staging of patients with chronic kidney disease (CKD) who received an intervention for delaying dialysis (intervention group) compared to controls at baseline and after 3 months of intervention.

\begin{tabular}{|c|c|c|c|}
\hline Factors & $\begin{array}{l}\text { Intervention group } \\
(\mathrm{n}=166)\end{array}$ & $\begin{array}{l}\text { Control group } \\
(\mathrm{n}=168)\end{array}$ & $\mathrm{p}$ value \\
\hline Baseline mean (SD) of eGFR & $47.01(8.31)$ & 53.75 (11.74) & $<0.001$ \\
\hline Mean (SD) eGFR at 3 months & 48.77 (10.08) & $47.89(8.85)$ & 0.395 \\
\hline $\begin{array}{l}\text { Mean (SD) differences of eGFR } \\
\text { from baseline }\end{array}$ & $+1.76(7.51)$ & $-5.85(9.03)$ & $<0.001$ \\
\hline $\begin{array}{l}\text { Decline of eGFR }>4 \mathrm{~mL} / \mathrm{min} / 1.73 \\
\mathrm{~m} 2 \text { after } 3 \text { months, } \mathrm{n}\end{array}$ & $27(16.27)$ & $90(53.57)$ & $<0.001$ \\
\hline Baseline CKD staging & & & $<0.001$ \\
\hline 2 & $4(2.41)$ & 49 (29.17) & \\
\hline $3 a$ & $98(59.04)$ & $81(48.21)$ & \\
\hline $3 b$ & $64(38.55)$ & $38(22.62)$ & \\
\hline CKD staging at 3 months & & & 0.124 \\
\hline 2 & $20(12.05)$ & $16(9.52)$ & \\
\hline $3 a$ & $96(57.83)$ & $94(55.95)$ & \\
\hline $3 b$ & $46(27.71)$ & $58(34.52)$ & \\
\hline 4 & $4(2.41)$ & 0 & \\
\hline $\begin{array}{l}\text { Differences of CKD stage from } \\
\text { baseline }\end{array}$ & & & $<0.001$ \\
\hline Improved by one stage & $40(24.10)$ & $10(5.95)$ & \\
\hline No progression & $112(67.47)$ & $97(57.74)$ & \\
\hline Declined by one stage & $14(8.43)$ & $59(35.12)$ & \\
\hline Declined by two stages & 0 & 2 (1.19) & \\
\hline
\end{tabular}

\section{Discussion}

This randomized control trial showed the benefits of employing a multidisciplinary approach in the treatment of CKD patients. The multidisciplinary treatment for up to stage $3 b$ CKD slowed CKD progression as evidenced by improvement in eGFR 
$\left(+1.76\right.$ vs $\left.-5.85 \mathrm{ml} / \mathrm{min} / 1.73 \mathrm{~m}^{2}\right)$ and the lower proportion of patients with eGFR decline $>4$ $\mathrm{ml} / \mathrm{min} / 1.73 \mathrm{~m}^{2}$ ) and led to improvements in CKD stage as shown in Table 3 . These benefits were statistically significant despite patients in the intervention group having more severe CKD at baseline. Baseline eGFR was significantly lower in the intervention group than the control group (47.01 vs $53.75 \mathrm{ml} / \mathrm{min} / 1.73 \mathrm{~m}^{2} ; \mathrm{p}$ value $\left.<0.001\right)$. And, there were higher proportions of patients with stage $3 \mathrm{a}$ (59.04\% vs $48.21 \%)$ and $3 b(38.55 \%$ vs $22.62 \%)$ CKD despite the use of a simple random sampling method. These differences highlight the benefits of the multidisciplinary approach.

A previous randomized controlled study showed that composite end-points, including eGFR, significantly improved after a self-management program that involved diet and exercise, but the difference in eGFR alone was not significant $(1.2 \%$ vs $11.2 \% ; p$ value $=0.209$ ) [16]. However, that study differed from the present study in some key respects. First, while the previous study enrolled patients with stage 3 and 4 CKD, this study only enrolled patients with up to stage $3 b$, which may have resulted in better outcomes. Second, the previous study only examined the self-management support system, while our study also implemented a delivery system, clinical information system, and decision support system. The specialized nurse and expert patients also played important roles in CKD care. A previous study found that the involvement of a single experienced renal nurse practitioner led to greater improvements in various renal surrogate outcomes, such as hemoglobin (11.6 vs $10.8 \mathrm{~g} / \mathrm{dL}, \mathrm{p}$ value < 0.05$)$ and serum albumin ( 3.4 vs $3.0 \mathrm{~g} / \mathrm{dL} ; \mathrm{p}$ value < 0.01$)$, compared with care provided by multiple nephrology trainees [17]. As was the case in this study, the renal nurse was better able to encourage the patients to stick to the treatment plan.

The strength of this study is that it was conducted as a randomized controlled trial and found benefits with regard to renal progression. As mentioned earlier, the benefits of multidisciplinary management in CKD are simple and cheap and it can save costs on healthcare, delay dialysis initiation, and reduce mortality [17]. This multidisciplinary management model is feasible in community hospitals. The team comprised of simple combination of internists, registered nurses, and pharmacists. These medical personnel are available in all levels of hospitals. Training of patients, special nurses, and caregivers are also required.

There were some limitations. First, the results of this study may only apply to community hospital settings and patients with CKD stage $3 \mathrm{~b}$ or lower.
Further studies may be needed to confirm these results in other more complicated setting such as tertiary care hospitals [18-20]. Second, as the primary outcomes were measured at three months, longer term evaluation may be necessary. Third, some factors associated with CKD treatment were not studied such as statin therapy or toxic substances [21-23]. However, the randomization process may have negated these issues. Fourth, the adherence rate was not evaluated. However, the benefits found may be significant regardless of adherence rate. Finally, there were some different factors at baseline despite randomized method. The outcomes of the study may be affected by these differences. For example, the intervention group had lower education level than the control group but better outcomes. These results may imply that education level may not affect the results of this multidisciplinary approach. Further studies are needed to confirm the results of this study.

In conclusion, this randomized controlled trial showed slower renal progression in patients with up to stage $3 b \quad C K D$ who were treated using a multidisciplinary approach.

\section{Acknowledgements}

The authors would like to thank Dr. Dylan Southard (USA) for his kind review on the final manuscript and support from Health Systems Research Institute (HSRI), Thailand.

\section{Competing Interests}

The authors have declared that no competing interest exists.

\section{References}

1. Stevens PE, Levin A; Kidney Disease: Improving Global Outcomes Chronic Kidney Disease Guideline Development Work Group Members. Evaluation and management of chronic kidney disease: synopsis of the kidney disease: improving global outcomes 2012 clinical practice guideline. Ann Intern Med. 2013;158:825-30.

2. Rashidi A, Sehgal AR, Rahman M, O'Connor AS. The case for chronic kidney disease, diabetes mellitus, and myocardial infarction being equivalent risk factors for cardiovascular mortality in patients older than 65 years. Am J Cardiol. 2008;102:1668-73.

3. Foley RN, Murray AM, Li S, Herzog CA, McBean AM, Eggers PW, et al. Chronic kidney disease and the risk for cardiovascular disease, renal replacement, and death in the United States Medicare population, 1998 to 1999. J Am Soc Nephrol. 2005;16:489-95.

4. Mihaylova B, Schlackow I, Herrington W, Lozano-Kühne J, Kent S, Emberson J, et al. Cost-effectiveness of Simvastatin plus Ezetimibe for Cardiovascular Prevention in CKD: Results of the Study of Heart and Renal Protection (SHARP). Am J Kidney Dis. 2016;67:576-84.

5. Epping-Jordan JE, Pruitt SD, Bengoa R, Wagner EH. Improving the quality of health care for chronic conditions. Qual Saf Health Care. 2004;13:299-305.

6. Ameh OI, Ekrikpo U, Bello A, Okpechi I. Current Management Strategies of Chronic Kidney Disease in Resource-Limited Countries. Int J Nephrol Renovasc Dis. 2020;13:239-51.

7. Wei SY, Chang YY, Mau LW, Lin MY, Chiu HC, Tsai JC, et al. Chronic kidney disease care program improves quality of pre-end-stage renal disease care and reduces medical costs. Nephrology (Carlton). 2010;15:108-15.

8. Curtis BM, Ravani P, Malberti F, Kennett F, Taylor PA, Djurdjev O, et al. The short- and long-term impact of multi-disciplinary clinics in addition to standard nephrology care on patient outcomes. Nephrol Dial Transplant. 2005;20:147-54. 
9. Wu IW, Wang SY, Hsu KH, Lee CC, Sun CY, Tsai CJ, et al. Multidisciplinary predialysis education decreases the incidence of dialysis and reduces mortality--a controlled cohort study based on the NKF/DOQI guidelines. Nephrol Dial Transplant. 2009;24:3426-33.

10. Yu YJ, Wu IW, Huang CY, Hsu KH, Lee CC, Sun CY, et al. Multidisciplinary predialysis education reduced the inpatient and total medical costs of the first 6 months of dialysis in incident hemodialysis patients. PLoS One. 2014;9:e112820.

11. Chen SH, Tsai YF, Sun CY, Wu IW, Lee CC, Wu MS. The impact of self-management support on the progression of chronic kidney disease--a prospective randomized controlled trial. Nephrol Dial Transplant. 2011;26:3560-6.

12. Jiamjariyapon T, Ingsathit A, Pongpirul K, Vipattawat K, Kanchanakorn S, Saetie A, et al. Effectiveness of Integrated Care on Delaying Progression of stage 3-4 Chronic Kidney Disease in Rural Communities of Thailand (ESCORT study): a cluster randomized controlled trial. BMC Nephrol. 2017;18:83.

13. Navaneethan SD, Jolly SE, Schold JD, Arrigain S, Nakhoul G, Konig V, et al. Pragmatic Randomized, Controlled Trial of Patient Navigators and Enhanced Personal Health Records in CKD. Clin J Am Soc Nephrol. 2017;12:1418-27.

14. Lopez-Vargas PA, Tong A, Howell M, Craig JC. Educational Interventions for Patients With CKD: A Systematic Review. Am J Kidney Dis. 2016;68:353-70.

15. Saudan P, Ponte B, Marangon N, Martinez C, Berchtold L, Jaques D, et al. Impact of superimposed nephrological care to guidelines-directed management by primary care physicians of patients with stable chronic kidney disease: a randomized controlled trial. BMC Nephrol. 2020;21:128.

16. Flesher M, Woo P, Chiu A, Charlebois A, Warburton DE, Leslie B. Self-management and biomedical outcomes of a cooking, and exercise program for patients with chronic kidney disease. J Ren Nutr. 2011;21:188-95.

17. Lee W, Campoy S, Smits G, Vu Tran Z, Chonchol M. Effectiveness of a chronic kidney disease clinic in achieving $\mathrm{K} / \mathrm{DOQI}$ guideline targets at initiation of dialysis--a single-centre experience. Nephrol Dial Transplant. 2007:22:833-8.

18. Jingmark S, Kuhirunyaratn P, Theeranut A, Nonjui P. Subjective well-being and related factors among community-dwelling elderly in Udon Thani Province, Thailand. Asia Pac J Sci Technol. 2020;25:APST-25-01-09.

19. Wangsan K, Chaiear N, Sawanyawisuth K, Klainin P, Simajareuk K. Pattern of shiftwork and health status among nurses in a university hospital in northeastern Thailand. Asia Pac J Sci Technol. 2019;24:APST-24-02-08.

20. Chaiear N, Nirarach K, Kawamatawong T, Krisorn P, Burge PS. Proportion of workers having work-related asthma symptoms in a cassava factory, Nakhon Ratchasima province, Thailand. Asia Pac J Sci Technol. 2020;25:APST-25-02-08.

21. Welch JL, Johnson M, Zimmerman L, Russell CL, Perkins SM, Decker BS. Self-management interventions in stages 1 to 4 chronic kidney disease: an integrative review. West J Nurs Res. 2015;37:652-78.

22. Kingkaew N, Antadech T. Cardiovascular risk factors and 10-year CV risk scores in adults aged 30-70 years old in Amnat Charoen Province, Thailand. Asia Pac J Sci Technol. 2019;24:APST-24-04-04.

23. Buttichak A, Leelayuwat N, Bumerraj S, Boonprakob Y. The effects of a yoga training program with fit ball on the physical fitness and body composition of overweight or obese women. Asia Pac J Sci Technol. 2019;24:APST-24-02-07. 